\section{Recombinant DNA is safe}

Professor R. H. Pritchard argues that there are no real hazards in recombinant $D N A$ research.

THE publication of the first report by the Genetic Manipulation Advisory Group has been the occasion for a number of articles in the press giving muted praise for the unprovocative, unemotive and constructive approach of we British to the problems posed by the attempt to control research with recombinant DNA. The Group has had an unenviable task and I would not wish to minimise the difficulties it has had in attempting to formulate rules that are acceptable to everyone concerned. Nevertheless, the occasion must not be allowed to pass without comment on the less commendable features of its Report and on the present level of debate on this issue in Great Britain.

The only conceivable justification for the expensive and growing bureaucracy which now controls recombinant DNA research would be that it posed an identifiable and distinct hazard to human health or society. Consequently it cannot be emphasised too of ten that no such hazard has ever been identified. Nor have I heard a sustainable theoretical argument to suggest that such hazards are real. Recent comment in the press and Parliament indicates a total misunderstanding of this point as witnessed by the fact that the so-called hazards have almost invariably been compared with those surrounding the nuclear energy industry. The difference between the two is unambiguous. The hazards of radiation are known from experience of them. They are quantifiable, and appropriate control can therefore be based on reasoned argument.

GMAG and other official bodies that have preceded it must take substantial responsibility for allowing such a widespread and fundamental confusion to exist and to continue to exist. Indeed, it is most disturbing that the GMAG report, if only by default, leaves the impression that there is broad agreement about the basic premises upon which its existence is based and that it need only concern itself with the definition and execution of regulations based upon thesc premises. Discussions I have had with many biologists indicate that some regard the recombinant DNA debate as the longest running and most expensive farce in town. Others accept the need for caution and control in the execution of certain kinds of experiments but believe that the GMAG guidelines are far too sweeping. Others believe that by confining their attention to in vitro recombinant DNA experiments the Group is operating in a logical vacuum with the result that if some of the conjectured hazards are real then the horse will probably have bolted before ever it enters their stable door. I have yet to meet a biologist who approves of the proposals as they stand. None of this divergence of views would be apparent to those readers of the GMAG Report who are not biologists. although it is they who will be most influenced by it.

The total absence of reasoned argument hased on observations has led to the most disturbing aspect of the whole debate. This is the continual resort to authority rather than to evidence as a justification for control. GMAG summarising the background to its birth tells us "In July 1974 a group of distinguished biologists drew public attention to these problems" (the hypothetical risks of recombinant DNA research). And later (para. 4). "The question of hazards was raised by responsible scientists and we feel it essential that, however strong an individual worker's intuitive feeling may be that the hazards have been grossly overestimated, we have a right to expect of him, until we know more of the reality of the situation, that he should do the work either with scrupulous care or not at all". Mere workers, apparently, who disagree with "distinguished" and "responsible" scientists can only have "intuitive" reasons for doing so.

I do not wish to question the distinction of the scientists concerned, but clearly it is they who acted upon intuition. It is my personal opinion that their intuition was unsound, that they were ill-informed and consequently, in view of their distinction, it is they who acted irresponsibly. The soundness of the suggestions made by these scientists has never been rigorously discussed by those in this country who have been asked to do so. The Working Party chaired by Lord Ashby was unable to identify the hazards of recombinant DNA research. The following Working Party under Sir Robert Williams nevertheless felt able to divide experiments into four categories of increasing risk. Now we find GMAG debating in its report whether DNA from birds should be categorised in terms of its hazard level with mammalian DNA (because birds are warm blooded) or with amphibian DNA (because of the closer evolutionary relationship). One is tempted to wonder why the group didn't consult the I Ching for advice.

Practising biologists will not find it easy to adhere to restrictive and time-consuming rules, and ensure that others do too, when there is so little confidence that these rules have a rational basis. Consequently, the question that now concerns us most is on what evidence and by what means will the controls be relaxed. On this question as on others surrounding the recombinant DNA debate there seems little ground for optimism.

Consider, for example, the suggestion by the distinguished scientists that the creation of novel antibiotic resistant phenotypes among bacterial species by in vitro recombination is a potential hazard. Antibiotic therapy has been in widespread use for decades. A consequence has been the development of resistant strains of pathogens and nonpathogens. Such strains can become the prevalent ones in hospital environments and are a hazardous nuisance. I am not aware, however, of a single example in all this time of any bacterial species in which resistance to any antibiotic has become the prevalent phenotype except in an antibiotic-contaminated environment. Is there a reasonable alternative to the supposition from these observations that there is a price to be paid for antibiotic resistance by a naturally sensitive species and that this price is too high for resistant strains to predominate without positive selection in their favour? If resistance confers no selective advantage, what is the cause for concern except the one which has always been with us? This is how best to employ antibiotics so as to take maximum advantage of the natural selection pressures against resistant organisms to minimise their prevalence. Had the resources devoted to the recombinant DNA debate been devoted instead to investigation of this latter question, an important medical problem might have been solved. Instead a bureaucracy has been created.

But to return to relaxation of controls. Is it likely that GMAG, or any other body. will ever have in its possession more convincing evidence than it has now that in vitro transfers of antibiotic resistance determinants present no hazards? I suspect not and therefore wonder how relaxation of the blanket controls of this kind of activity are ever to be relaxed if they are not to be removed immediately. Moreover, if relaxation here proves a problem, then how much greater a problem will it prove to be in the case of the more esoteric areas of conjecture?

Great Britain will, from 1 August, have the doubtful privilege of being the first country to bring recombinant DNA research under legislative control. I find it hard to understand why GMAG has not publicly and firmly advised that this legislation be deferred until there is evidence, or even broad agreement, that the postulated hazards do indeed exist. 